\title{
Empleo y desempleo de las víctimas de violencia de género: garantías y facilidades de acceso y mantenimiento del empleo en España*
}

\author{
Employment and unemployment of victims of gender \\ violence: guarantees and facilities of access \\ and maintenance of employment in Spain
}

\author{
Elena García Testal ${ }^{* *}$ \\ Universitat de València \\ ORCID ID: 0000-0003-3069-0631
}

Recibido: 13/1/2021

Aceptado: 24/2/2021

doi: https://doi.org/10.20318/labos.2021.6217

Resumen: La violencia de género también tiene repercusiones en el empleo. El trabajo puede convertirse en un instrumento o recurso útil para las víctimas, a las que confiere independencia profesional, económica, personal y social. Pero la relación de trabajo de las víctimas se resiente como consecuencia de la violencia, de modo que si la voluntad es su protección integral deviene necesario atender los aspectos laborales de su prestación de servicios, en el caso de las víctimas empleadas. Pero también es ineludible atender a las víctimas en situación de desempleo, facilitar su inserción en el mercado de trabajo; un acceso al trabajo dificultado por los prejuicios y discriminaciones en la contratación de mujeres víctimas de violencia de género, labor en la que debe implicarse a empresas y administraciones públicas. La LO 1/2004, de 28 de diciembre, de protección integral contra la violencia de género (LOVG), que se planteó como objetivo completar la atención a las víctimas de la violencia de género, alcanza el ámbito laboral a través de distintas medidas de fomento, garantía de acceso y mantenimiento del empleo, medidas que pueden ser revisadas con vistas a su perfeccionamiento.

Palabras clave: violencia de género, víctimas, género, empleo, desempleo, protección integral.

Abstract: $\quad$ Gender-based violence also has an impact on employment. Work can become a useful tool or resource for victims, providing them with professional, economic, personal and social independence. But the victims' employment relationship suffers as a result of the violence so that if the purpose is their comprehensive

\footnotetext{
*Trabajo realizado en el marco del I+D de Generación del Conocimiento sobre Violencia, Trabajo y Género (VITRAGE), Ref. PGC2018-094912-B-I00, del Programa Estatal de Generación del Conocimiento y fortalecimiento científico y tecnológico del sistema del I+D+i del Ministerio de Ciencia, Innovación e Universidades.

**elena.garcia@uv.es
} 
protection, it becomes necessary to address the labour aspects of their provision of services, in the case of employed victims. But it is also unavoidable to attend the victims in unemployment situations, to facilitate their insertion in the job market; access to work that was made difficult by prejudice and discrimination when hiring women victims of gender violence, a task in which companies and public administrations must be involved. LO 1/2004, of December 28, on comprehensive protection against gender-based violence (LOVG), whose objective was to complete the care for victims of gender-based violence, reaches the workplace through different measures of promotion, guarantees of access and maintenance of employment, measures that can be revised seeking its further development.

Keywords: $\quad$ gender violence, victims, gender, employment, unemployment, integral protection.

\section{Violencia de género y trabajo: la influencia de la violencia en el trabajo}

En el año 2020 se publicó la Macroencuesta de violencia contra la mujer ${ }^{1}$ que incluye una valoración del impacto que la violencia tiene en la relación de trabajo de las víctimas de la violencia de género. El capítulo 8 de la Parte I del Informe de resultados se dedica a las "Consecuencias físicas, psíquicas y laborales de la violencia en la pareja" señalando los porcentajes de absentismo laboral consecuencia de la violencia en el ámbito de la pareja en los siguientes términos:

"8.7 Absentismo laboral como consecuencia de la violencia en la pareja. El 15,6\% de las mujeres que han sufrido VFSEM ${ }^{2}$ de una pareja o expareja estuvieron una época sin poder acudir a su lugar de trabajo o estudio como consecuencia de los episodios de violencia $(6,1 \%$ entre las que han padecido la violencia de la pareja actual y $17,4 \%$ en el caso de la violencia de parejas pasadas). El 21,0\% de las mujeres que han sufrido violencia física o sexual de alguna pareja o expareja, estuvieron una época sin poder acudir a su lugar de trabajo o estudio como consecuencia de los episodios de violencia $(9,4 \%$ en el caso de la violencia de la pareja actual, $22,2 \%$ entre las que la han padecido de parejas pasadas)."3

Además, a estos datos se añaden otros que ponen de manifiesto la necesidad de atención médica y psicológica a las víctimas, que también repercuten sobre la asistencia al trabajo de éstas: así, el 46,6\% de las mujeres que han sufrido violencia física y/o violencia sexual de alguna pareja actual o pasada ha experimentado lesiones ${ }^{4}$; de las que el $10 \%$ de las que sufrieron violencia de la pareja actual recibieron asistencia médica y el 7,6\% declara no haberla recibido, pero sí que la hubieran necesitado; y los datos ascienden al 23,6\% y $14,9 \%$ de las que sufrieron violencia de parejas

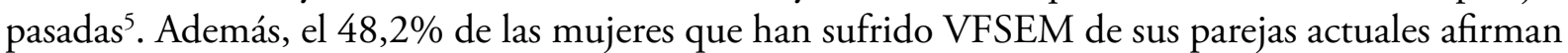

${ }^{1}$ Realizada por la Subdirección General de Sensibilización, Prevención y Estudios de la Violencia de Género (Delegación del Gobierno contra la Violencia de Género), se trata de la única estadística oficial para medir la prevalencia de la violencia contra la mujer. Se realiza aproximadamente cada 4 ańos desde 1999 y está incluida en el Plan Estadístico Nacional, principal instrumento ordenador de la actividad estadística de la Administración General del Estado.

La Delegación del Gobierno contra la Violencia de Género ha sido la encargada de su elaboración en las ediciones de 2011, 2015 y 2019. Puede consultarse en https://violenciagenero.igualdad.gob.es/violenciaEnCifras/macroencuesta2015/pdf/Macroencuesta_2019_ estudio_investigacion.pdf

${ }^{2}$ VFSEM: Violencia física, sexual, emocional o han sentido miedo de sus parejas.

${ }^{3}$ Macroencuesta de violencia contra la mujer-2019, Subdirección General de Sensibilización, Prevención y Estudios de la Violencia de Género (Delegación del Gobierno contra la Violencia de Género, Ministerio de Igualdad, 2020, p. 89.

${ }^{4}$ Macroencuesta de violencia contra la mujer-2019, p. 82.

${ }^{5}$ Macroencuesta de violencia contra la mujer-2019, p. 87. 
haber tenido consecuencias psicológicas y el $74,7 \%$ entre las que padecieron la violencia de parejas pasadas ${ }^{6}$. Finalmente, en cuanto a las consecuencias sobre la salud de la violencia en la pareja el $44,9 \%$ de las mujeres que han sufrido violencia física o sexual de alguna pareja afirma haber sufrido ansiedad o angustia con frecuencia en los 12 meses previos a la entrevista ${ }^{7}$, lo que se evidencia que la violencia de género tiene consecuencias en la salud de las mujeres afectadas, lo que aumenta la frecuencia de atención sanitaria ${ }^{8}$.

Por su parte, el Informe Adecco-Un Empleo contra la Violencia-2019 ${ }^{9}$ puso de manifiesto el alto porcentaje de mujeres víctimas de violencia que se encuentran en situación de desempleo:

La gran mayoría se encuentra en situación de desempleo 61\%, de las cuales la mitad (50,6\%) está en situación de paro de larga duración. Por otro lado, del 19,8\% de las encuestadas que tiene un empleo, el 69,4\% lleva menos de 1 año con el empleo y solo un 30,6\% lleva más de 2 años.

La precariedad económica $(72,3 \%)$ y la baja autoestima $(56,3 \%)$ son dos de las situaciones con las que más se sienten identificadas. El 85\% encuentra dificultad para llegar a fin de mes.

Por ello se evidencia que "el empleo se alza como un recurso importante para la mujer víctima de la violencia de género, al empoderar transversalmente a las mujeres, incrementando su autonomialindependencia (74\%), seguridad (48\%), autoestima (44\%), y aportando estabilidad (37\%)"10. Se constata en este sentido cómo la falta de inserción en el ámbito laboral añade precariedad económica a las víctimas de violencia de género que dificulta salir del círculo de la violencia ${ }^{11}$.

Para las víctimas el trabajo puede devenir de vital importancia para asegurar el éxito de la lucha contra la violencia de género pues favorece la independencia económica ${ }^{12}$, la incorporación al trabajo permite además el alejamiento del agresor, la independencia profesional y la mejora de la autoestima personal ${ }^{13}$. Siendo esto así, y viendo cómo la violencia de género condiciona la vinculación de las víctimas con el trabajo, bien deteriorando la relación laboral, bien provocando la pérdida del puesto de trabajo ${ }^{14}$, bien dificultando la inserción laboral, la respuesta legislativa al fenómeno de la violencia de género resultaría incompleta si no se integraran en la LOVG los efectos que esta situación produce sobre la relación de empleo de la víctima o no se adoptaran medidas destinadas a atenuar o eliminar el impacto que produce sobre la relación de trabajo ${ }^{15}$.

El objetivo de la LOVG era la protección integral de las víctimas de violencia de género a través de la prevención, la sanción y la atención a las mujeres, a sus hijos menores y a los menores

${ }^{6}$ Macroencuesta de violencia contra la mujer-2019, p. 87.

${ }^{7}$ Macroencuesta de violencia contra la mujer-2019, p. 91.

${ }^{8}$ Macroencuesta de violencia contra la mujer-2019, p. 93.

${ }^{9}$ ADECCO, Un empleo contra la Violencia, 2019, p. 15. Puede consultarse en https://s03.s3c.es/imag/doc/2019-11-22/informeempleo-contra-la-violencia-2019.pdf

${ }^{10}$ ADDECO, Un empleo contra la Violencia, citado, p. 18. En 2020 la Fundación Adecco publica un nuevo informe que pone el acento en los efectos del COVID-19 sobre las víctimas, señalando que "durante el ańo de la pandemia, el aislamiento ha disparado esta lacra social que, paradójicamente, ha permanecido más silenciada e invisible que nunca", con un descenso en el número de denuncias no vinculado a una disminución de los casos de violencia de género. Puede consultarse en https://fundacionadecco.org/ wp-content/uploads/2019/11/informe-empleo-contra-la-violencia-2020.pdf

${ }^{11}$ SERRANO ARGÜESO, M., "¿Por qué la elección entre inserción laboral o ayudas económicas específicas? Lo que el Pacto de Violencia de Género no ha sido capaz de ver”, Revista General de Derecho del Trabajo y de la Seguridad Social, núm. 49 (2018), p. 414.

${ }^{12}$ MELLA MÉNDEZ, L., Prologo en AAVV, Violencia de género y derecho del trabajo, Estudios Actuales sobre puntos críticos, (Dir. L. MELLA MÉNDEZ), editorial La Ley, Madrid, 2012, p. 27.

${ }^{13}$ MELLA MÉNDEZ, L., "La suspensión por violencia de género del contrato de la trabajadora por cuenta ajena: algunos puntos críticos", en Mujer, trabajo y Seguridad Social (Borrajo Dacruz, director), ed. La Ley, Madrid, 2010, p. 419.

${ }^{14}$ CABEZA PEREIRO, J., "El concepto y rasgos de la violencia de género. Particularidades desde el derecho del trabajo", en Violencia de género y derecho del trabajo, Estudios Actuales sobre puntos críticos, citado, p. 97-98.

15 GARCIA ROMERO, B., "La violencia de género desde la perspectiva del derecho del trabajo y de la seguridad social", en Aranzadi Social no 11/2012 (parte estudio). 
sujetos a su tutela, o guarda y custodia. La inclusión de una serie de medidas en el ámbito de los derechos laborales y de protección social -dentro del Título II dedicado a los Derechos de las víctimas- deviene inevitable e imprescindible.

Debe finalizarse este apartado haciendo una referencia al Convenio núm. 190 de la OIT, sobre violencia y acoso en el mundo del trabajo, aprobado en junio de 2019 junto a la Recomendación complementaria (núm. 206), sobre el que España ha anunciado ratificación, por lo que sería preciso revisar el marco jurídico interno para valorar la posibilidad de ratificación inmediata o la necesidad de introducir modificaciones legislativas en el ámbito interno ${ }^{16}$. No parece que el nuevo Convenio 190 OIT haya apostado totalmente por amparar laboralmente las anteriores situaciones de violencia a las que nos referimos. En efecto, pese a su amplio ámbito de aplicación, si atendemos a la delimitación que efectúa el art. 3 del Convenio 190 OIT respecto a la violencia y acoso a los que se aplica la norma, apreciamos esa falta de atención a los efectos laborales de la violencia producida fuera del trabajo, pues este Convenio se aplica a la violencia y el acoso en el mundo del trabajo que ocurren durante el trabajo, en relación con el trabajo o como resultado del mismo; especificando este elemento de forma amplia: a) en el lugar de trabajo, inclusive en los espacios públicos y privados cuando son un lugar de trabajo; b) en los lugares donde se paga al trabajador, donde éste toma su descanso o donde come, o en los que utiliza instalaciones sanitarias o de aseo y en los vestuarios; c) en los desplazamientos, viajes, eventos o actividades sociales o de formación relacionados con el trabajo; d) en el marco de las comunicaciones que estén relacionadas con el trabajo, incluidas las realizadas por medio de tecnologías de la información y de la comunicación; e) en el alojamiento proporcionado por el empleador, y f) en los trayectos entre el domicilio y el lugar de trabajo; pero sin incluir los efectos que la violencia producida fuera del trabajo, en el ámbito doméstico, familiar o de pareja, pueda tener en el trabajo. Ciertamente, debe hacerse mención al art. 10.f del Convenio que se refiere a la obligación de los Estados Miembros de adoptar medidas para "reconocer los efectos de la violencia doméstica y, en la medida en que sea razonable y factible, mitigar su impacto en el mundo del trabajo", pero es ésta la única referencia directa, además del Preámbulo, de manera que estas escasas referencias parecen dejar vacía de protección las repercusiones laborales de la violencia en el ámbito doméstico; restringida, limitada y remitida a la Recomendación 206 OIT, que como se sabe, carece de carácter vinculante ${ }^{17}$. Comparto la opinión crítica manifestada respecto de la posibilidad de incidir más directamente en la inclusión de la violencia doméstica y las medidas de protección laboral ${ }^{18}$.

\section{Víctimas y violencia de género}

Debe comenzarse, sin embargo, haciendo una precisión: la LOVG solo se aplica a algunas víctimas de violencia sobre las mujeres, las que quedan dentro de su ámbito de aplicación concretado en el artículo 1 de la LOVG, y centrado en la violencia -todo acto de violencia física y psicológica, incluidas las agresiones a la libertad sexual, las amenazas, las coacciones o la privación arbitraria de libertad-exclusivamente cuando se ejerce sobre las mujeres por parte de quienes sean o hayan sido sus cónyuges

\footnotetext{
${ }^{16}$ Sobre los conceptos de violencia en el ámbito del Convenio OIT véase PONS CARMENA, M. "Aproximación a los nuevos conceptos sobre violencia y acoso en el trabajo a partir de la aprobación del Convenio OIT 190”, en Labos, Vol. 1, Núm. 2, pp. 3060; YAGÜE BLANCO, S. "Convenio 190 de la OIT sobre violencia y acoso: delimitación de su ámbito de aplicación ante la posible ratificación por España”, Revista General de Derecho del Trabajo y de la Seguridad Social, 2020, núm. 57, pp. 499-538.

${ }^{17}$ YAGÜE BLANCO, S. "Convenio 190 de la OIT sobre violencia y acoso: delimitación de su ámbito de aplicación ante la posible ratificación por España”, citado, pp. 527 y ss.

${ }^{18}$ YAGÜE BLANCO, S. "Convenio 190 de la OIT sobre violencia y acoso: delimitación de su ámbito de aplicación ante la posible ratificación por España”, citado, p. 529.
} 
o de quienes estén o hayan estado ligados a ellas por relaciones similares de afectividad, aun sin convivencia. Además, la condición de víctima debe acreditarse conforme a las previsiones del art. 23 de la LOVG ${ }^{19}$.

La exigencia de relación conyugal o de pareja, presente o pasada, entre agresor y víctima, deja fuera de la protección de la LOVG a una amplia serie de situaciones de violencia contra las mujeres, que seguramente también deben valorarse como manifestaciones de discriminación, desigualdad y consecuencia de las relaciones de poder de los hombres sobre las mujeres: no se incluyen los actos de violencia ejercidos por otros varones -que no sean o hayan sido pareja de la víctima-, dentro o fuera del ámbito familiar o doméstico ${ }^{20}$, ni tampoco las situaciones de violencia entre parejas del mismo sexo - por no tratarse de una manifestación de la dominación del hombre sobre la mujer-. Finalmente, no sólo queda al margen de la LOVG la violencia ejercida en el ámbito doméstico por otros sujetos o hacia otros sujetos, sino que también recibe un tratamiento distinto la violencia ejercida en el ámbito laboral ${ }^{21}$. La violencia de género en el trabajo constituye una conducta pluriofensiva que además de suponer la violación de derechos fundamentales, constituye un riesgo para la salud laboral ${ }^{22}$. En el caso de las relaciones de trabajo, la protección contra actos de violencia ejercidos en el espacio laboral por sujetos que no mantienen relación de afectividad como pareja o expareja, se encuentra en la normativa laboral sobre acoso ${ }^{23}$, esto es, en la Ley 62/2003, de 30 de diciembre, pero sobre todo en la Ley Orgánica 3/2007, de 22 de marzo, para la igualdad efectiva de mujeres y hombres (LOI), respecto de la que la LOVG fue una precursora ${ }^{24}$. La no inclusión de este tipo de

\footnotetext{
${ }^{19}$ Señala el art. 23 LOVG, en su redacción vigente tras la reforma operada por el Real Decreto-Ley 9/2018, de 3 de agosto: "Las situaciones de violencia de género que dan lugar al reconocimiento de los derechos regulados en este capítulo se acreditarán mediante una sentencia condenatoria por un delito de violencia de género, una orden de protección o cualquier otra resolución judicial que acuerde una medida cautelar a favor de la víctima, o bien por el informe del Ministerio Fiscal que indique la existencia de indicios de que la demandante es víctima de violencia de género. También podrán acreditarse las situaciones de violencia de género mediante informe de los servicios sociales, de los servicios especializados, o de los servicios de acogida destinados a víctimas de violencia de género de la Administración Pública competente; o por cualquier otro título, siempre que ello esté previsto en las disposiciones normativas de carácter sectorial que regulen el acceso a cada uno de los derechos y recursos. El Gobierno y las Comunidades Autónomas, en el marco de la Conferencia Sectorial de Igualdad, diseńaran, de común acuerdo, los procedimientos básicos que permitan poner en marcha los sistemas de acreditación de las situaciones de violencia de género". Sobre la cuestión de la acreditación de las situaciones de violencia, más ampliamente, en GARCIA TESTAL, E., Derechos de las trabajadoras víctimas de violencia de género, Valencia, 2014.

En los Tribunales del Orden Social sobre la necesidad de acreditación véase STSJ Madrid de 9 de septiembre de 2020 (rec. 329/2020); STSJ País Vasco de 22 de enero de 2020 (rec. 2259/2019); STSJ del País Vasco de 2 de febrero de 2010 (rec. 3021/2009).

Distinta es la situación de la acreditación de la condición de víctima de violencia de género respecto al acceso a la pensión de viudedad, pues el art. 220.1, párrafo tercero, de la LGSS señala que "En todo caso, tendrán derecho a la pensión de viudedad las mujeres que, aun no siendo acreedoras de pensión compensatoria, pudieran acreditar que eran víctimas de violencia de género en el momento de la separación judicial o el divorcio mediante sentencia firme, o archivo de la causa por extinción de la responsabilidad penal por fallecimiento; en defecto de sentencia, a través de la orden de protección dictada a su favor o informe del Ministerio Fiscal que indique la existencia de indicios de ser víctima de violencia de género, así como por cualquier otro medio de prueba admitido en Derecho.", como se analiza en GARCIA TESTAL, E., "Violencia de género y pensión de viudedad: la acreditación de las situaciones de violencia de género”, en Lex Social, núm. 8, 2018. También en MENÉNDEZ SEBASTIÁN, P., Beneficiarios de la pensión de viudedad, Cizur Menor-Navarra, 2020, p. 230-232.

${ }^{20}$ MENÉNDEZ SEBASTIÁN/VELASCO PORTERO: "La suspensión del contrato de trabajo de las víctimas de violencia de género como medida de protección integral. Mucho ruido y pocas nueces", en Revista de Trabajo y Seguridad Social, CEF, núm. 271, no 55/2005, p.13.

${ }^{21}$ Vid MELLA MÉNDEZ, L., "La suspensión por violencia de género del contrato de la trabajadora por cuenta ajena: algunos puntos críticos", en Mujer, trabajo y Seguridad Social (Borrajo Dacruz, director), ed. La Ley, Madrid, 2010, pp. 420 y 421 . Señalando la necesidad de que una ley integral contra la violencia de género debería abarcar cualquier acto de violencia que sufran las mujeres SOBRINO GONZÁLEZ, G.M., La protección laboral de la violencia de género: déficits y ventajas, Valencia 2013.

${ }^{22}$ PÉREZ DEL RIO, M. ${ }^{a}$ T., La violencia de género en el ámbito laboral: el acoso sexual y el acoso sexista, Bomarzo, Albacete, 2009, p. 41.

${ }^{23}$ Son dos las modalidades que puede presentar la violencia de género en el trabajo: el acoso sexual y el acoso por razón de sexo. Sobre la cuestión SÁNCHEZ TRIGUEROS, C., "La violencia de género en el trabajo. Perspectiva de Seguridad Social”, en Revista General de Derecho del Trabajo y de la Seguridad Social, no 14/2007, pp. 12 y ss.

${ }^{24}$ CABEZA PEREIRO, J., "El concepto y rasgos de la violencia de género. Particularidades desde el derecho del trabajo", en MELLA MÉNDEZ, L. (dir.) Violencia de género y derecho del trabajo: estudios actuales sobre puntos criticos, editorial La Ley, Madrid,
} 
violencia en la LOVG puede considerarse una opción del legislador por un marco regulador más especializado, efectuando la transposición de la Directiva 72/2003, de 23 de septiembre de 2002, sobre discriminación por razón de género en el acceso al empleo y las condiciones de trabajo ${ }^{25}$. La LOI introduce modificaciones en el ordenamiento laboral para ofrecer respuestas adecuadas a los casos de violencia que se producen en la empresa por compañeros de trabajo o por el empresario ${ }^{26}$.

Este panorama legislativo pone de manifiesto un tratamiento para las víctimas de violencia de género, de acuerdo con la LOVG, y uno distinto para las mujeres víctimas de otras situaciones de violencia ajenas a la LOVG. Sin embargo, y de acuerdo con el art. 1 del Convenio del Consejo de Europa sobre prevención y lucha contra la violencia contra la mujer y la violencia doméstica, hecho en Estambul el 11 de mayo de 2011, es conveniente ofrecer los mismos niveles de protección a las víctimas de todas las formas de violencia ${ }^{27}$. A efectos de este Convenio, el concepto de "violencia contra la mujer" se define como "una violación de los derechos humanos y una forma de discriminación contra las mujeres, y se designarán todos los actos de violencia basados en el género que implican o pueden implicar para las mujeres daños o sufrimientos de naturaleza física, sexual, psicológica o económica, incluidas las amenazas de realizar dichos actos, la coacción o la privación arbitraria de libertad, en la vida pública o privada"; y por "violencia doméstica" se entienden "todos los actos de violencia física, sexual, psicológica o económica que se producen en la familia o en el hogar o entre cónyuges o parejas de hecho antiguos o actuales, independientemente de que el autor del delito comparta o haya compartido el mismo domicilio que la víctima”. Así, tal y como señala el art. 18 del Convenio "Las Partes tomarán las medidas legislativas u otras necesarias para proteger a todas las víctimas contra cualquier nuevo acto de violencia”, y es en este sentido en el que cabe efectuar el requerimiento de modificación normativa de unificación del tratamiento protector de las víctimas.

Esta delimitación de la protección de las víctimas de violencia de género debe incluir una referencia al Pacto de Estado en materia de violencia de género, aprobado en $2017^{28}$ por el Gobierno, las CCAA y la Federación Española de Municipios y Provincias para el impulso de las políticas de erradicación de la violencia sobre la mujer y la construcción de una sociedad libre de violencia sobre las mujeres. El Pacto incluye 11 ejes de actuación, que van desde la realización de acciones de sensibilización y prevención al perfeccionamiento de la asistencia, ayuda y protección que se ofrece a las víctimas (eje 3) en el que se incluye el impulso de los planes de inserción laboral y la necesaria implicación de los agentes sociales. El Real Decreto-Ley 9/2018, de 3 de agosto, de medidas urgen-

2012, p. 96: "Tiene mucho de simbólico que la LOVG haya precedido a la LO 3/2007. Es algo más que una casualidad. En el fondo, revela un programa que atiende a la secuencia lógica de la Cumbre de Beijing: la lucha contra la violencia es lo primero. $Y$ no solo porque sea lo más intolerable y lo más indigno, sino porque su erradicación constituye un presupuesto de la igualdad.".

${ }^{25}$ GARCIA ROMERO, B., "La violencia de género desde la perspectiva del derecho del trabajo y de la seguridad social", en Aranzadi Social no 11/2012 (parte estudio).

${ }^{26}$ La protección de las víctimas de violencia en el trabajo ha de tratar de garantizar la protección de su salud laboral, la recuperación de la autoestima laboral, la reparación de la víctima y la sanción al agresor. El conjunto de medidas laborales se puede plantear desde la perspectiva preventiva, en el marco de la protección frente a los riesgos laborales, y en una perspectiva reparadora de la víctima y de protección de su relación laboral. Como se sabe, el artículo 7 de la LOI define los conceptos de acoso sexual y acoso por razón de sexo, en los siguientes términos: 1. Sin perjuicio de lo establecido en el Código Penal, a los efectos de esta Ley constituye acoso sexual cualquier comportamiento, verbal o fisico, de naturaleza sexual que tenga el propósito o produzca el efecto de atentar contra la dignidad de una persona, en particular cuando se crea un entorno intimidatorio, degradante u ofensivo. 2. Constituye acoso por razón de sexo cualquier comportamiento realizado en función del sexo de una persona, con el propósito o el efecto de atentar contra su dignidad y de crear un entorno intimidatorio, degradante u ofensivo. 3. Se considerarán, en todo caso, discriminatorios el acoso sexual y el acoso por razón de sexo. 4. El condicionamiento de un derecho o de una expectativa de derecho a la aceptación de una situación constitutiva de acoso sexual o de acoso por razón de sexo se considerará también acto de discriminación por razón de sexo. Véase por todos, ALTÉS TÁRREGA, JA, El acoso del trabajador en la empresa, Valencia, 2008; y PÉREZ DEL RIO, T., La violencia de género en el ámbito laboral: el acoso sexual y el acoso sexista, citada, p. 22 y ss.

${ }^{27}$ Instrumento de ratificación del Convenio del Consejo de Europa sobre prevención y lucha contra la violencia contra la mujer y la violencia doméstica, hecho en Estambul el 11 de mayo de 2011 en BOE de 6 de junio de 2014.

${ }^{28}$ Puede consultarse https://violenciagenero.igualdad.gob.es/pactoEstado/home.htm 
tes para el desarrollo del Pacto de Estado contra la violencia de género desarrolló algunas de estas medidas, modificando algunos preceptos de la LOVG.

A este panorama normativo ha venido a sumarse el Convenio núm. 190 de la OIT, sobre violencia y acoso en el mundo del trabajo, al que ya se ha hecho referencia. El amplio enfoque del Convenio OIT 190 genera una ambiciosa consecuencia: todas las personas que trabajan han de quedar protegidas, con independencia de su situación contractual y de sus características persona$l_{\text {es }}^{29}$, y es que una de las virtualidades del Convenio 190 OIT es, precisamente, la delimitación de un ámbito de protección frente al acoso y la violencia considerablemente más amplio que el previsto en el marco normativo internacional, supranacional y nacional, tanto en su dimensión material, como personal y espacio-temporal ${ }^{30}$. Incluso el concepto de violencia de género puede ser objeto de revisión ${ }^{31}$. A efectos del Convenio 190 OIT "la expresión "violencia y acoso por razón de género" designa la violencia y el acoso que van dirigidos contra las personas por razón de su sexo o género, o que afectan de manera desproporcionada a personas de un sexo o género determinado, e incluye el acoso sexual." Así, la violencia de género no se identifica con la violencia contra las mujeres; las víctimas de la violencia de género, en el Convenio 190 OIT también pueden ser hombres, relacionándose con los conceptos de identidad de género y orientación sexual. Ahora bien, no puede desconocerse que las principales víctimas son mujeres y los perpetradores, en su mayoría, hombres, pues lo contrario sería desconocer que la violencia de género femenino está instaurada de forma mayoritaria en la sociedad, con repercusión en las relaciones de trabajo ${ }^{32}$.

\section{La protección de las víctimas de violencia de género trabajadoras y la inserción de las vícti- mas desempleadas}

Si abordamos la protección de las víctimas de violencia de género en la LOVG, el acercamiento debe hacerse en función de su situación laboral. Dos tipos de problemas laborales se detectan. Por un lado, se constata una escasa incorporación de las víctimas de violencia de género al mundo laboral ${ }^{33}$. Por otro lado, la utilización de los derechos laborales por las víctimas es escaso ${ }^{34}$. De ello se deriva la necesidad de diferentes medidas, unas destinadas a mantener la relación laboral, compatibilizando el trabajo con la situación de violencia de género, otras destinadas a incentivar la incorporación al empleo de las víctimas desempleadas.

Para las víctimas con empleo por cuenta ajena, la normativa debe estar destinada a la protección de sus derechos laborales, el mantenimiento de su puesto de trabajo -pese a las especiales circunstancias de su vida personal-, aunque ello suponga una modificación de las condiciones de trabajo con el objetivo de facilitar la protección de su vida o salud, o bien facilitando el cese temporal, en la prestación de servicios. En este sentido la LOVG se centra en dos situaciones: la primera,

\footnotetext{
${ }^{29}$ PONS CARMENA, M., "Aproximación a los nuevos conceptos sobre violencia y acoso en el trabajo a partir de la aprobación del Convenio OIT 190", citado, p. 57.

${ }^{30}$ YAGÜE BLANCO, S. "Convenio 190 de la OIT sobre violencia y acoso: delimitación de su ámbito de aplicación ante la posible ratificación por España”, citado, p. 518 y ss.

${ }^{31}$ Sobre la cuestión, RAMOS QUINTANA, MI., "Enfrentar la violencia y el acoso en el mundo del trabajo: la discusión normativa de la OIT”, Revista del Ministerio de Trabajo, Migraciones y Seguridad Social, núm. 138, p. 94.

${ }^{32}$ RAMOS QUINTANA, MI., "Enfrentar la violencia y el acoso en el mundo del trabajo: la discusión normativa de la OIT", citado, p. 94.

${ }^{33}$ El 70 Informe Addeco: Un empleo contra la violencia, citado, p. 15, señala que "la gran mayoría de las víctimas se encuentra en situación de desempleo, $61 \%$, de las cuales la mitad (50,6\%) está en situación de paro de larga duración”.

${ }^{34} \mathrm{Si}$ tomamos en consideración los datos aportados por el $7^{\circ}$ Informe Addeco: Un empleo contra la violencia 2019 un elevado porcentaje de víctimas de violencia de género -el 80,6\%- no se ha acogido a ninguno de los derechos profesionales por ser víctima de violencia de género, y un 48,6 \% desconocía disponer de dichos derechos (pp. 18 y 19).
} 
la trabajadora puede mantener su relación de trabajo, pero debe cohonestarlo con las medidas necesarias para garantizar su protección o su derecho a la asistencia social integral, por lo que se articulan medidas de conciliación en relación con el tiempo y el lugar de trabajo; la segunda, la trabajadora no puede mantener su relación de trabajo, temporal o definitivamente, por lo que se le facilita la suspensión y/o extinción de su contrato de trabajo. Del mismo modo para aquellas víctimas que son funcionarias públicas, y con idéntica finalidad, se incorporan medidas con las peculiaridades que derivan de la prestación de servicios en el empleo público ${ }^{35}$. Por su parte, las opciones de las víctimas con empleo por cuenta propia las medidas de protección han de plantearse de forma distinta, atendiendo así a las especialidades del trabajo autónomo.

Para las víctimas de violencia de género que no tienen empleo, o se encuentran desarrollando un trabajo de forma informal, la perspectiva ha de ser la de facilitar su inserción laboral, protección a la que se refiere el art. 22 de la LOVG, y que se desarrolló en el RD 1917/2008, de 21 de noviembre, con un programa específico de inserción sociolaboral para las víctimas de violencia de género.

\subsection{La protección laboral de las trabajadoras víctimas de violencia de género}

Las opciones que la trabajadora víctima de violencia de género puede barajar para hacer efectiva su protección o su derecho a la asistencia social integral, afectan al tiempo de trabajo -que podrá reordenar o reducir-, a la variación del lugar de trabajo -que podrá modificar-, así como medidas protectoras relativas a la posibilidad de interrumpir temporal -suspensión del contrato con reserva de su puesto de trabajo- o extinguir definitivamente su actividad laboral -extinción con tratamiento especial-, y finalmente medidas de protección frente a decisiones injustificadas del empresario. Es el artículo 21 de la LOVG el que anuncia las distintas opciones para las trabajadoras, mientras que su desarrollo lo encontramos en la Disposición Adicional 7a de la LOVG.

3.1.1. Modificaciones contractuales para hacer efectiva la protección de la trabajadoras víctima de violencia de género

Para las trabajadoras víctimas de violencia de género, la LOVG prevé la posibilidad de introducir modificaciones en la relación laboral, bien del tiempo de trabajo, bien del lugar de trabajo, con el objetivo de permitir la compatibilidad del trabajo con su condición de víctimas violencia de género.

Se trata de modificaciones a iniciativa de la trabajadora -que debe acreditar ante el empresario su condición de víctima de violencia de género-, y que están sujetas a los límites legales, a las previsiones convencionales e incluso a las "fórmulas existentes en la empresa".

Las modificaciones del tiempo de trabajo se refieren a dos aspectos ${ }^{36}$ : la opción por la reducción de jornada (reducción número de horas de trabajo acompañada de reducción salarial, que lleva aparejado el gran inconveniente de no protegerse mediante la prestación por desempleo parcial

\footnotetext{
${ }^{35}$ BELANDO GARÍN, B. "La evolución de los derechos de las funcionarias ante la violencia de género: el ejemplo valenciano", en La prevención y erradicación de la violencia de género: un estudio multidisciplinar y forense, coord. Elena Martínez García, Juan Carlos Vegas Aguilar, Francisco Javier Boix Reig, 2012, págs. 267-283.

${ }^{36} \mathrm{La}$ consideración de esta ausencias o faltas puntualidad como justificadas y no computables como absentismo ha perdido virtualidad tras la derogación del art. 52.d ET por el Real Decreto-ley 4/2020, de 18 de febrero, posteriormente convalidado por la Ley $1 / 2020$, de 15 de julio.

No obstante, es preciso señalar que no se traslada el coste de las ausencias al empresario, ya que se trata de ausencias no retribuidas. Además, se impone a la trabajadora la necesidad de comunicación, aunque no de preavisar: a la empresa "a la mayor brevedad" (art. 21.4 LOVG).
} 
por lo que no se atiende la pérdida salarial que conlleva; reducción de jornada prevista en los art. 21.1 LOVG y art. 37.8 ET ); y la reordenación de jornada, a la que se refiere el art. 21.1 LO y que permitiría a la trabajadora una redistribución del tiempo de trabajo y de descanso ${ }^{37}$.

La compatibilidad del trabajo y la condición de víctima de violencia de género también puede exigir modificaciones del lugar de trabajo, a las que se refieren los arts. 21.1 LOVG y el actual art. 40.4 ET. En realidad, de acuerdo con estas previsiones legislativas sólo existe una preferencia a ocupar otro puesto de trabajo en otro centro de trabajo, lo que sólo podrá darse en los supuestos en que e la empresa tenga más de un centro de trabajo, siempre que existan vacantes de mismo grupo o categoría equivalente, y con una duración inicialmente temporal 6 meses -durante los cuales se reserva el puesto de origen- y a partir de ese momento puede convertirse en una modificación definitiva, a iniciativa de la trabajadora. Al empresario le incumbe la comunicación de las vacantes presentes o futuras y la reserva de puesto origen. Esta movilidad puede exigir la sustitución de la trabajadora mediante una contratación de interinidad que se acompaña de bonificación de cuotas de la Seguridad Social, como señala el art. 21.3 de la LOVG.

En cuanto a la modificación de las condiciones de la prestación de servicios también debe en la actualidad hacerse referencia a la opción por el trabajo a distancia -fuera de los establecimientos habituales de la empresa-, pudiendo atender a las previsiones del Real Decreto-ley 28/2020, de 22 de septiembre. Cabe destacar la nota de voluntariedad que rige el acceso al trabajo a distancia de acuerdo con la sección $1^{\text {a }}$ de 1 Capítulo II del Real Decreto-Ley 28/2020, y que adquiere especial relevancia en el caso de las víctimas de violencia de género, tanto en los supuestos de convivencia con el agresor, como en aquellos en que la víctima necesita una resocialización. Esta misma norma ha modificado los términos del mencionado art. 37.8 ET para incluir el derecho de las víctimas de violencia de género a realizar su trabajo total o parcialmente a distancia o a dejar de hacerlo si este fuera el sistema establecido, siempre en ambos casos que esta modalidad de prestación de servicios sea compatible con el puesto y funciones desarrolladas por la persona. Como se aprecia en la redacción del art. 37.8 ET se ha reflejado la especial voluntariedad que debe concurrir tanto en el acceso al trabajo a distancia como en el cese de esta modalidad de prestación de servicios ${ }^{38}$. Pues bien, debe señalarse que la modificación del art. 37.8 ET para incluir, entre los derechos de las víctimas de violencia de género, el derecho a trabajar a distancia o a dejar de hacerlo, se debe configurar como una excepción a la voluntariedad que la regulación vigente del trabajo a distancia ha venido a establecer, debiendo ceder la voluntariedad empresarial en beneficio de la protección de la víctima de violencia de género, aunque el ejercicio del derecho quede vinculado a las cautelas generales de tomar en consideración los términos previstos en la negociación colectiva o en el acuerdo con la empresa, así como a la opción judicial para la resolución de las discrepancias. En este sentido, puede tenerse en cuenta que la regulación del trabajo a distancia recuerda que "En la elaboración de medidas para la protección de las víctimas de violencia de género, deberán tenerse especialmente en cuenta, dentro de la capacidad de actuación empresarial en este ámbito, las posibles consecuencias y particularidades de esta forma de prestación de servicios en aras a la protección y garantía de derechos sociolaborales de estas personas" (art. 4 del RDL 28/2020).

\footnotetext{
${ }^{37}$ Sobre la necesidad de que la negativa de la empresa al cambio solicitado debe basarse en razones materiales, causa organizativa o productiva, en supuesto de conciliación de trabajo y violencia de género, véase la STSJ Andalucía-Granada de 28 de marzo de 2019, rec. 1898/2018.

${ }^{38}$ Sobre la voluntariedad en el trabajo a distancia debe consultarse LÓPEZ BALAGUER, M., "Voluntariedad del trabajo a distancia: el acuerdo de trabajo a distancia”, en AAVV (dir. LÓPEZ BALAGUER) El trabajo a distancia en el RDL 28/2020, Valencia, 2020, pp. 87 a 116.
} 


\subsubsection{La incompatibilidad del trabajo y la condición de víctima de violencia de género}

Como medidas alternativas o subsidiarias se facilita el cese temporal en la prestación de servicios, a través de la suspensión del contrato con reserva de puesto de trabajo ${ }^{39}$ (así se deriva del art. 21.1 LOVG y se concreta en los arts. 45.1.n y 48.10 ET y en la LGSS) con una duración inicial máxima de 6 meses (duración que va a depender de la voluntad de la trabajadora víctima de violencia de género); que admite prórrogas (en este caso con intervención judicial, de 3 meses y hasta 18 meses). La suspensión del contrato de trabajo sabemos que conlleva una pérdida de salario, pero esta circunstancia se protege mediante la percepción de prestación por desempleo (art. 267.1.b.2 LGSS).

También se facilita el cese definitivo en la prestación de servicios, extinción del contrato por voluntad de la trabajadora, dimisión que se incorpora en la letra m del art. 49.1 ET, con dos diferencias fundamentales con la dimisión común: la comunicación formal a la empresa no requiere un plazo de preaviso y, además, se prevé la protección de la pérdida salarial, mediante el acceso a la prestación por desempleo (art. 267.1.a.5 LGSS).

\subsubsection{La protección frente a decisiones injustificadas del empresario}

La consideración de una trabajadora como víctima de violencia de género puede lesionar la relación laboral, deteriorarla y originar en el empresario la voluntad de adoptar decisiones extintivas. Para proteger a la trabajadora frente a posibles decisiones injustificadas de la empresa la LOVG adopta una fórmula ya conocida en nuestro ordenamiento jurídico laboral relativa a la protección frente al despido (disciplinario u objetivo), incluyéndose un nuevo supuesto de nulidad de la decisión empresarial: el de las trabajadoras víctimas de violencia de género por el ejercicio de los derechos de reducción o reordenación de su tiempo de trabajo, movilidad geográfica, de cambio de centro de trabajo o de suspensión de la relación laboral, salvo que se declare la procedencia del despido (53.4.b y 55.5.b del ET). Se pretende así proteger a la víctima de violencia de género frente a decisiones injustificadas del empresario, sin necesidad de acreditar un móvil discriminatorio ni vulneración de derechos fundamentales ${ }^{40}$.

El sistema adoptado se configura condicionado a las víctimas que han hecho uso de alguno de los derechos tasados legalmente; no se acude a una fórmula general de protección automática de las trabajadoras víctimas de violencia de género, sino solamente se protege a la trabajadora que ejerce sus derechos, para que no pueda ser represaliada por ello mediante una extinción del contrato que pueda ser declarada improcedente $-y$ en consecuencia indemnizada $-{ }^{41}$. De esta manera, para que sea efectiva esta causa de nulidad, la trabajadora no sólo ha de acreditar su condición de víctima de violencia de género, sino que además debe haber hecho uso de los derechos que la legislación le atribuye por su condición de víctima de violencia de género, de tal modo que se cree la relación entre la decisión de la empresa -el despido- y la condición de víctima ${ }^{42}$. Así, es preciso

\footnotetext{
39 Sobre petición errónea de excedencia, véase la STSJ Aragón de 2 de octubre de 2019, rec. 441/2019, que estimó debía interpretarse la concurrencia en la trabajadora de un claro error sustancial, de derecho y excusable, y la obligación de la empresa de informar adecuadamente.

${ }^{40}$ En sentido contrario, si la trabajadora plantea la existencia de una discriminación por razón de sexo, no será necesario acreditar el ejercicio de derechos reconocidos a las víctimas de violencia de género en la LOVG, sino indicios que generen una apariencia de discriminación, debiendo el empresario probar la existencia de un motivo razonable de despido; un ejemplo en la STSJ Islas Canarias-Las Palmas de 10 de julio de 2019 (rec. 388/2019)

${ }^{41}$ SEMPERE NAVARRO, AV, "Cinco casos recientes sobre colectivos vulnerables (prostitutas, extranjeros, víctimas de violencia de género, discapacitados, jubilados forzosos", en Aranzadi Social no 14/2008, p. 2 de 3.

42 STSJ Cataluña de 28 de enero de 2010 (rec. 5668/2009). También PERÁN QUESADA, S, "La protección de la trabajadora víctima de violencia de género ante el despido. Comentario a la Sentencia del TSJ de Cataluña (Sala de lo Social), de 3 de octubre de 2008”, en Aranzadi Social 58/2008 (westlaw.es, BIB 2008/2789), p. 3 de 5.
} 
que la empresa conozca la situación, pues sólo de ese modo es posible entender que la empresa ha tratado de lesionar el derecho de la trabajadora. A la trabajadora corresponde aportar prueba indiciaria, y a la empresa aportar una justificación objetiva y razonable, suficientemente probada de la medida adoptada y de su proporcionalidad ${ }^{43}$, no vinculada con la situación de violencia de género ni con el uso de los derechos que corresponden. Se otorga así a la trabajadora una tutela adicional durante los períodos de ejercicio de los derechos mencionados que se proyecta al ámbito de la carga probatoria ante la presunción de nulidad derivada del hecho de haberse producido la extinción durante el período protegido ${ }^{44}$. Como puede apreciarse no se trata de una inmunidad de las trabajadoras ante decisiones extintivas del empresario, sino que, solamente se produce una inmunidad ante decisiones injustificadas del empresario.

\subsection{La protección de las víctimas de violencia de género funcionarias}

Los artículos 24, 25 y 26 de la LOVG se dedican al reconocimiento de derechos a las funcionarias víctimas de violencia de género, que se completan con las modificaciones que la DA 9a de la misma ley introdujo en la Ley 30/1984, de 2 de agosto, para su adecuación al contenido de la LOVG. Sin embargo, estos preceptos de la Ley 30/1984, de 2 de agosto, fueron derogados por la Disposición Derogatoria de la Ley 7/2007, de 12 de abril, que aprueba el Estatuto Básico del Empleado Público (EBEP), y sustituidos por preceptos del propio EBEP. El texto actualmente vigente lo constituye el aprobado por el Real Decreto Legislativo 5/2015, de 30 de octubre, que aprueba el texto refundido de la Ley del Estatuto Básico del Empleado Público

Los artículos 24 y 25 de la LOVG reconocen los siguientes derechos a las funcionarias víctimas de violencia de género: el derecho a la reducción o a la reordenación de su tiempo de trabajo; el derecho a la movilidad geográfica de centro de trabajo; el derecho a la excedencia y la justificación de las faltas de asistencia al trabajo motivadas por la situación física o psicológica derivada de la violencia de género. El conjunto se completa con el artículo 26 de la LOVG que establece como los medios de acreditación de la condición de víctima de violencia de género ${ }^{45}$.

Pues bien, los derechos que la LOVG reconoce a las funcionaras víctimas de violencia de género, y que en la actualidad desarrolla el Estatuto Básico del Empleado Público (EBEP), se pueden agrupar en derechos vinculados al tiempo de trabajo; derechos vinculados a la modificación del lugar de trabajo y, finalmente la excedencia de la funcionaria víctima de violencia de género.

${ }^{43}$ STSJ Castilla La Mancha de 2 de noviembre de 2007 (rec. 1117/2007).

${ }^{44}$ STSJ Cataluńa de 3 de octubre de 2008 (rec. 587/2007). En este supuesto la extinción se produce cuando la trabajadora se encuentra de baja por depresión motivada por el acoso de su antigua pareja, alegando la empresa que la trabajadora "realizaba vida totalmente normal durante la baja". Previamente a la baja laboral la trabajadora había solicitado y obtenido del Juzgado de Violencia Doméstica sobre la mujer número 1 de Barcelona auto de medidas cautelares en cuya parte dispositiva impone a su pareja la prohibición de aproximarse a menos de 500 metros de ella. Además, obtuvo del empresario resolución favorable a la solicitud de cambio de turno (de nocturno a jornada completa en diurno). El Tribunal entiende que se dan los presupuestos normativos de los que se deriva su cualificada situación frente a la posterior decisión disciplinaria del empresario; y así, aunque la trabajadora se encontrara en ese momento en situación de incapacidad temporal hay que considerarla como ejerciente de los derechos de adaptación de tiempo de trabajo, por lo que le resulta aplicable la garantía de nulidad del artículo 55.5.b ET. Y ello porque la causa alegada por la empresa imputándole a la trabajadora el haber "realizado vida totalmente normal" carece de entidad disciplinaria dado que la baja médica se debe a "patología de trastorno de ansiedad generalizado secundario a violencia de género". Sobre esta sentencia SEMPERE NAVA$\mathrm{RRO}, \mathrm{AV}$, "Cinco casos recientes sobre colectivos vulnerables (prostitutas, extranjeros, víctimas de violencia de género, discapacitados, jubilados forzosos", en Aranzadi Social no 14/2008, p. 2 de 3.

${ }^{45}$ Se defendió, sin embargo, la necesidad de matizar, eliminar o suavizar este requisito, al menos en las situaciones iniciales de violencia en que se tutele a la víctima, aunque no se recurra al procedimiento legal, de tal forma que al menos las ausencias al trabajo se entiendan justificadas y probadas por cualquier medio admisible en derecho. En este sentido, FERNÁNDEZ LÓPEZ, MF, "La violencia de género y el régimen de la función pública. Una construcción inacabada de su régimen jurídico”, en Relaciones Laborales, Revista crítica de teoría y práctica, no 10, 2008. 
Se ha señalado que la ley en lugar de tener en cuenta las peculiaridades del régimen jurídico de las funcionarias víctimas de violencia de género lo que trata de hacer es equiparar la tutela a la de las trabajadoras por cuenta ajena, lo que provoca defectos de cobertura ${ }^{46}$.

El artículo 24 de la LOVG establece el derecho de la funcionaria víctima de violencia de género a la reducción o reordenación de su tiempo de trabajo, precepto que se desarrolla en el art. 49 letra d del EBEP a través de un permiso de trabajo para las funcionarias víctimas de violencia de género. Se trata de un permiso por razón de violencia de género sobre la mujer funcionaria, que va a implicar que sus faltas de asistencia, totales o parciales, tendrán la consideración de justificadas por el tiempo y en las condiciones en que así lo determinen los servicios sociales de atención o de salud según proceda. Se trata de conceder un trato especial, al no considerarse incumplimiento estas faltas de asistencia o de puntualidad, por lo que no deberá sufrir descuento en su retribución ni podrán ser sancionadas ${ }^{47}$. Debe señalarse que la aplicación de este régimen jurídico sólo será posible en aquellas ausencias vinculadas de forma directa con el recurso de la víctima a los servicios sociales y de salud, exigiéndose además que sean éstos quienes determinen el tiempo y las condiciones de estas ausencias, lo que ha sido objeto de crítica doctrinal ${ }^{48}$.

Asimismo, se reconoce el derecho a la reducción de la jornada con disminución proporcional de la retribución, para hacer efectiva su protección o su derecho de asistencia social integral. Se trata de un derecho en aras de hacer efectiva su protección integral; derecho no sometido a requerimientos complementarios de necesidad del servicio ni a otra apreciación, más que la de la funcionaria afectada ${ }^{49}$. Ahora bien, consecuencia inmediata del ejercicio de este derecho por la funcionaria víctima de violencia de género es la reducción proporcional de su jornada y su retribución, por lo supondrá para ella una obvia merma de ingresos. No se establecen parámetros mínimos ni máximos de reducción ${ }^{50}$, pero sí una vinculación causal entre el derecho y la finalidad del mismo: se trata de garantizar la protección de la funcionaria víctima de violencia de género o su derecho de asistencia social integral. Podrá hacerse efectiva mediante una reducción de la jornada diaria, semanal o mensual, esto es, aunque pueda resultar más habitual la reducción en el número de horas al día en que se prestan servicios, también es posible que se reduzcan los días de asistencia al trabajo a la semana o al mes. Como garantía, el art. $49 \mathrm{~d}$ EBEP establece que la funcionaria pública mantendrá sus retribuciones íntegras cuando reduzca su jornada en un tercio o menos.

Finalmente, se reconoce un derecho a la reordenación del tiempo de trabajo, a través de la adaptación del horario, de la aplicación del horario flexible o de otras formas de ordenación del tiempo de trabajo que sean aplicables, en los términos que para estos supuestos establezca la Administración Pública competente en casa caso. La primera cuestión que llama la atención es que no se trata de un derecho incondicionado, ejercitable dependiendo exclusivamente de la voluntad de la funcionaria, sino que queda condicionado a las disposiciones de la Administración ${ }^{51}$. Se establecen

${ }^{46}$ FERNÁNDEZ LÓPEZ, M.F., "La violencia de género y el régimen de la función pública. Una construcción inacabada de su régimen jurídico”, en Relaciones Laborales, Revista crítica de teoría y práctica, no 10,2008 . Véase también respecto al personal laboral al servicio de las Administraciones Públicas, MENÉNDEZ SEBASTIÁN, P. "La fijación de condiciones laborales en el ámbito público”, en BLASCO PELLICER/LÓPEZ BALAGUER (dirs.), Las relaciones laborales en el sector público, Valencia, 2019, pp. 173-174 y 190-194.

${ }^{47}$ RODRIGUEZ ESCANCIANO, S., "La protección de la funcionaria víctima de violencia de género", Tribuna Social, no 185/2006, pp. 30 y ss.

${ }^{48}$ FERNÁNDEZ LÓPEZ, M.F., "La violencia de género y el régimen de la función pública. Una construcción inacabada de su régimen jurídico", en Relaciones Laborales, Revista crítica de teoría y práctica, no 10, 2008.

vFERNÁNDEZ LÓPEZ, M.F., "La violencia de género y el régimen de la función pública. Una construcción inacabada de su régimen jurídico", citado.

${ }^{50}$ RODRIGUEZ ESCANCIANO, S., "La protección de la funcionaria víctima de violencia de género", citado, p. 35.

${ }^{51}$ FERNÁNDEZ LÓPEZ, M.F., "La violencia de género y el régimen de la función pública. Una construcción inacabada de su régimen jurídico", citado. 
varias posibilidades de reordenación de la jornada de trabajo: adaptación del horario, aplicación de horario flexible y otras formas aplicables, pero se trata de un derecho que se ejercitará vinculado a las posibilidades de la Administración, por tanto a las necesidades del servicio, lo que requerirá un ajuste entre las necesidades del servicio y las de la funcionaria víctima de violencia de género, de forma que resulte adecuadamente valorado el derecho de ésta, lo que exige, en su caso, una denegación expresa y motivada, dado que restringe un derecho que la ley reconoce a la funcionaria ${ }^{52}$. Será la funcionaria la que deba elegir la fórmula que pueda resultar más eficaz para garantizar su protección o su derecho a la asistencia social. Una vez concedido no se fija normativamente una duración temporal, de manera que sería posible la adscripción a la nueva fórmula de ordenación del tiempo de trabajo con duración coincidente con la situación de la funcionaria víctima, en función de la permanencia de las circunstancias que condicionan su situación de víctima de violencia de género. Interesante resulta la remisión que, para el ejercicio de estos derechos establece el art. $49 \mathrm{~d}$ EBEP, al establecer que se realizará "en los términos que para estos supuestos establezca el plan de igualdad de aplicación o, en su defecto, la Administración Publica competente en cada caso", lo que parece exigir un protocolo previo a través del Plan de Igualdad u otro instrumento establecido en cada Administración Pública.

Por su parte, el artículo 24 de la LOVGse refiere al derecho de la funcionaria víctima de violencia de género a la movilidad geográfica. Es el artículo 82 del EBEP el que se refiere a la movilidad por razón de violencia de género, en los siguientes términos:

1. Las mujeres víctimas de violencia de genero que se vean obligadas a abandonar el puesto de trabajo en la localidad donde venían prestando sus servicios, para hacer efectiva su protección o el derecho a la asistencia social integral, tendrán derecho al traslado a otro puesto de trabajo propio de su cuerpo, escala o categoría profesional, de análogas características, sin necesidad de que sea vacante de necesaria cobertura. Aun así, en tales supuestos la Administración Pública competente, estará obligada a comunicarle las vacantes ubicadas en la misma localidad o en las localidades que la interesada expresamente solicite.

Se trata de facilitar el cambio de lugar de prestación de servicios a las mujeres víctimas de violencia de género, para hacer efectiva su protección o el derecho a la asistencia social integral, de forma paralela a la regulación de las trabajadoras por cuenta ajena, pero con las peculiaridades derivadas de tratarse de un servicio prestado para la Administración Pública en régimen funcionarial ${ }^{53}$. Este traslado tendrá la consideración de traslado forzoso, la movilidad tiene como resultado la permanencia en el puesto al que es trasladada, perdiendo su derecho respecto a la plaza de origen ${ }^{54}$; la funcionaria tendrá derecho a que se le respeten sus retribuciones y condiciones esenciales de trabajo y las indemnizaciones establecidas para los traslados forzosos ${ }^{55}$. Y finalmente debe considerarse además la limitación de las funcionarias públicas cuya movilidad geográfica está limitada además al territorio en que opera la Administración correspondiente, lo que tendrá menor repercusión en la Administración estatal o autonómica, pero será decisiva en la Administración local ${ }^{56}$.

\footnotetext{
${ }^{52}$ La motivación debe evidenciar que la Administración se ha planteado el ejercicio del derecho en términos de razonabilidad y proporcionalidad, evitando manifestaciones genéricas, como señala FERNÁNDEZ LÓPEZ, M.F., "La violencia de género y el régimen de la función pública. Una construcción inacabada de su régimen jurídico”, citado.

${ }^{53}$ Por todos, MORENO MÁRQUEZ, A., "La movilidad de la funcionaria víctima de violencia de género tras el Estatuto Básico del Empleado Público", en Aranzadi Social, no 7/2008 (Estudio), BIB 2008/1460, westlaw.es, p. 3/13.

${ }^{54}$ FERNÁNDEZ LÓPEZ, M.F., "La violencia de género y el régimen de la función pública. Una construcción inacabada de su régimen jurídico", citado.

${ }^{55}$ MORENO MÁRQUEZ, A., "La movilidad de la funcionaria víctima de violencia de género tras el Estatuto Básico del Empleado Público", citado, p. 7 de 13.

${ }^{56}$ FERNÁNDEZ LÓPEZ, M.F., "La violencia de género y el régimen de la función pública. Una construcción inacabada de su régimen jurídico", citado. No obstante, se ha planteado si es posible la movilidad interadministrativa de la funcionaria víctima de violencia de género, al amparo del artículo 84 EBEP, aunque reconociendo que no existe obligación de incluirse podría hacerse
} 
En las actuaciones y procedimientos relacionados con la violencia de género, se protegerá la intimidad de las víctimas, en especial, sus datos personales, los de sus descendientes y las de cualquier persona que esté bajo su guarda o custodia. Esta previsión obliga a la Administración a mantener confidencialidad sobre el proceso de modificación del lugar de trabajo, en todas sus fases, sin dar publicidad a sus actuaciones. La necesidad de mantener secreto sobre estas informaciones se constituye en un elemento para garantizar la integridad física de la víctima de violencia de género. Como consecuencia de ello la comunicación de las vacantes deberá efectuarse de forma individualizada, y las actuaciones y/o procedimientos que sigan a esa movilidad deberán caracterizarse por la ausencia de publicidad, evitando que esa información llegue al agresor ${ }^{57}$

Y, por último, el artículo 24 de la LOVG reconoce el derecho a la excedencia vinculada a la condición de víctima de violencia de género. El art. 89 del EBEP se refiere a la excedencia por razón de violencia de género, que permite a la funcionaria dejar de prestar servicios, de forma temporal, sin requerir el consentimiento de la Administración -ya que se configura como un derecho de la funcionaria ${ }^{58}$ - y que le concede la reserva de su puesto de trabajo. Se trata de una categoría independiente de los otros modelos de excedencia, reconocida de forma generosa por el legislador en cuanto los requisitos establecidos para su disfrute ${ }^{59}$.

El régimen previsto en la norma se desarrolla en los siguientes términos: Las funcionarias víctimas de violencia de género tendrán derecho a solicitar la situación de excedencia, sin tener que haber prestado un tiempo mínimo de servicios previos y sin que sea exigible plazo de permanencia en la misma (a diferencia del resto de supuestos de excedencia en los que sí se exige una prestación previa de servicios $\left.{ }^{60}\right)$.Durante los seis primeros meses tendrán derecho a la reserva del puesto de trabajo que desempeñarán, siendo computable dicho período a efectos de antigüedad, carrera y derechos del régimen de Seguridad Social que sea de aplicación. Cuando las actuaciones judiciales lo exigieran se podrá prorrogar este periodo por tres meses, con un máximo de dieciocho. Se garantiza la retribución durante el período inicial de duración del período: durante los dos primeros meses de esta excedencia la funcionaria tendrá derecho a percibir las retribuciones íntegras y, en su caso, las prestaciones familiares por hijo a cargo. Esta garantía retributiva durante un período de 2 meses constituye una novedad del EBEP con respecto al régimen inicialmente incluido en la Ley 30/1984, de 2 de agosto, pero sin duda es insuficiente, y la falta de ingresos se convierte, sin duda, en un elemento desincentivado de este recurso, calificado de inadvertencia de la ley, abierta laguna de notable magnitud ${ }^{61}$.

\subsection{La protección del trabajo por cuenta propia}

Situación distinta es la de las víctimas de violencia de género que sean trabajadoras por cuenta propia o autónomas. Habría que destacar que la LOVG apenas contenía previsiones para las trabajadoras autónomas, lo que producía un claro desequilibrio respecto de las trabajadoras por cuenta

a través del denominado Convenio de Conferencia Sectorial u otros instrumentos de colaboración. En este sentido, MORENO MÁRQUEZ, A., "La movilidad de la funcionaria víctima de violencia de género tras el Estatuto Básico del Empleado Público", citado, p. $9 / 13$

${ }^{57}$ MORENO MÁRQUEZ, A., "La movilidad de la funcionaria víctima de violencia de género tras el Estatuto Básico del Empleado Público", citado, p. 8/13.

${ }^{58}$ RODRIGUEZ ESCANCIANO, S., "La protección de la funcionaria víctima de violencia de género", citado, p. 36.

${ }^{59}$ BELANDO GARÍN, B., "Función pública y realidad social. La nueva adaptación del régimen jurídico de los funcionarios públicos realizada por la Ley Integral contra la Violencia de Género", en AAVV, coord. BOIX REIG/MARTÍNEZ GARCIA, La nueva Ley contra la violencia de género (LO 1/2004, de 28 de diciembre), Iustel, Madrid, 2005, p. 468 y ss.) señala como tales la inexistencia de período de carencia y de período de disfrute.

${ }^{60}$ RODRIGUEZ ESCANCIANO, S, "La protección de la funcionaria víctima de violencia de género", citado, p. 37.

${ }^{61}$ FERNÁNDEZ LÓPEZ, MF, "La violencia de género y el régimen de la función pública. Una construcción inacabada de su régimen jurídico", citado. 
ajena $^{62}$, pero la situación cambio ligeramente cuando se aprueba el Estatuto del Trabajo Autónomo -Ley 20/2007, de 11 de julio-, aunque solamente respecto de las trabajadoras autónomas económicamente dependientes.

Solo dos referencias en la LOVG: el artículo 21.5 que incorpora el cese de actividad -temporal o definitivo- como la vía de protección de la trabajadora autónoma; y el artículo 22 que determinó que en el marco del programa específico de empleo para las víctimas de violencia de género se debían incluir medidas para favorecer el inicio de una nueva actividad por cuenta propia.

De estas previsiones se deriva que sólo el cese en la actividad se configura como mecanismo útil para las trabajadoras autónomas víctimas de violencia de género, pues en este caso se derivan las medidas siguientes:

1. suspensión de la obligación de cotización durante un período máximo de seis meses. Nótese que se trata de un periodo máximo de seis meses, lo que permitirá a la trabajadora hacer uso de un período inferior pero no de un período superior -a diferencia de la suspensión del contrato de la trabajadora por cuenta ajena ${ }^{63}$-. Finalizado el período de suspensión de la obligación de cotizar se obliga a la trabajadora autónoma a optar entre reiniciar su actividad -aunque el riesgo de agresión o su situación personal no hayan sido resueltas- o mantener la suspensión sin conservación de los derechos de cotización, con la correspondiente laguna de cotización.

2. consideración de ese período como de cotización efectiva a efectos de las prestaciones de Seguridad Social. A estos efectos se tomará una base de cotización equivalente al promedio de las bases cotizadas durante los seis meses previos a la suspensión de la obligación de $\operatorname{cotizar}^{64}$. Se toma en consideración la propia cotización de la trabajadora autónoma víctima de violencia de género, y no las bases mínimas de cotización previstas en el régimen especial de trabajadores autónomos o por cuenta propia.

3. situación asimilada al alta. Además, este período tendrá la consideración de situación asimilada al alta (artículo 21.5 de la LOVG), aunque la norma nada indica sobre el contenido y alcance de esta situación ${ }^{65}$.

La trabajadora deberá acreditar que ha cesado en su actividad, mediante declaración escrita de la solicitante de haber cesado o interrumpido su actividad económica o profesional prestando declaración sobre la persona que gestiona directamente el establecimiento mercantil, industrial o de otra naturaleza de la que es titular, o en su caso, sobre el cese temporal o definitivo de la actividad. Y junto a ello deberá acreditar su condición de víctima de violencia de género en los términos señalados en el artículo 23 de la LOVG. De tratarse de una trabajadora autónoma económicamente dependiente, aquella declaración podrá ser sustituida por la comunicación escrita del cliente del que dependa económicamente en la que se hará constar el cese o la interrupción de la actividad. Tanto la declaración como la comunicación han de contener la fecha a partir de la cual se ha producido el cese o la interrupción ${ }^{66}$.

${ }^{62}$ POLO SÁNCHEZ, MC, "La trabajadora autónoma víctima de violencia de género: el marco de protección socioeconómico en el ejercicio de actividades por cuenta propia”, en AAVV, MORGADO PANADERO (Dir.), Trabajo Autónomo e Igualdad: Reflexiones desde el Derecho del Trabajo, Aranzadi-Thomson Reuters, Cizur Menor (Navarra), 2010, pp. 121-122.

${ }^{63}$ Así debería efectuarse una equiparación con los períodos de suspensión de contrato de trabajo y de cese de actividad de trabajadora autónoma, como se ha señalado por GALA DURÁN, C, "Violencia De género y Derecho del Trabajo: una aproximación a las diversas medidas previstas", Relaciones Laborales, núm. 1, 2005.

${ }^{64}$ Se genera la duda de qué ocurre si no acredita el mínimo de seis meses de cotización. POLO SÁNCHEZ, MC, "La trabajadora autónoma víctima de violencia de género: el marco de protección socioeconómico en el ejercicio de actividades por cuenta propia”, citado, p. 126.

${ }^{65}$ BARRIOS BAUDOR, GL, "Violencia de género y trabajadoras autónomas: período de cotización ficticia y situación asimilada al alta por violencia de género", citado, p. 584 y ss.

${ }^{66}$ Artículo 6 de la Ley 32/2010. 
Durante el período de cese temporal o definitivo es posible que la trabajadora acceda a la prestación de cese por actividad. La Ley 32/2010, de 5 de agosto, estableció un sistema específico de protección por cese de actividad de los trabajadores autónomos, que, además de reiterar la suspensión de la obligación de cotizar, regula una prestación económica para cubrir esas situaciones de cese originadas por la violencia de género a la trabajadora autónoma ${ }^{67}$.

La aprobación del ETA por la Ley 20/2007 supone la incorporación de medidas destinadas a la protección de las trabajadoras autónomas económicamente dependientes - de acuerdo con el art. 11que sean víctimas de la violencia de género. Así para las víctimas TRADE, son varios los preceptos de la Ley 20/2007 que resultan aplicables: el artículo 14, en relación con el tiempo de trabajo, regula el derecho a la adaptación del horario de actividad con el objeto de hacer efectiva su protección o su derecho a la asistencia social integral. Esta previsión deberá entenderse en sentido amplio -horarios flexibles de trabajo, distribución irregular de la jornada semanal, reparto del descanso semanal, interrupciones de la jornada anual...-, y, además, deberá ser la trabajadora autónoma económicamente dependiente la que adopte la decisión respecto de su tiempo de trabajo y actividad; el artículo 16 considera causa justificada de interrupción de la actividad la situación de violencia de género, para que la trabajadora autónoma haga efectiva su protección o su derecho a la asistencia social integral, lo que permitirá justificar ausencias o interrupciones para acceder a los servicios integrales de protección -servicios de salud o de asistencia social; y, finalmente, el artículo 15 añade que la relación contractual podrá extinguirse por decisión de la trabajadora autónoma económicamente dependiente que se vea obligada a extinguirla como consecuencia de ser víctima de violencia de género -esto es, como medio de garantía de protección de su integridad física-. Esta medida se adoptará cuando se ponga en evidencia la imposibilidad de mantener la actividad profesional de la trabajadora autónoma económicamente dependiente mientras permanezca el riesgo sobre su vida o integridad física ${ }^{68}$.

A estas previsiones pueden añadirse las de los arts. $32^{69}$ y 32 bis $^{70}$ del ETA, que tras la modificación incorporada por el RDL 28/2018, de 28 de diciembre, para la revalorización de las pensiones públicas y otras medidas urgentes en materia social, laboral y de empleo, se refieren a reducciones de duración temporal sobre la cotización por contingencias comunes para, entre otros colectivos, víctimas de violencia de género que causen alta inicial o que no hubieran estado en situación de alta en los 2 años inmediatamente anteriores, a contar desde la fecha de efectos del alta, en el Régimen Especial de la Seguridad Social de los Trabajadores por Cuenta Propia o Autónomos y para la cotización a la Seguridad Social de los trabajadores por cuenta propia agrarios incluidos en el Sistema Especial para Trabajadores por Cuenta Propia Agrarios.

\subsection{La protección e inserción de las víctimas de violencia de género desempleadas}

La LOVG, y posteriores normas de desarrollo estatal y autonómico ${ }^{71}$, han diseñado un sistema de

\footnotetext{
${ }^{67}$ Situación que la propia ley 32/2010 extiende a las socias trabajadoras de cooperativas de trabajo asociado, así como a las trabajadoras autónomas que ejerzan su actividad profesional conjuntamente con otros en régimen societario o bajo cualquier otra forma jurídica admitida en derecho.

${ }^{68}$ POLO SÁNCHEZ, MC, "La trabajadora autónoma víctima de violencia de género: el marco de protección socioeconómico en el ejercicio de actividades por cuenta propia”, citado, p. 139.

${ }^{69}$ Beneficios en la cotización a la Seguridad Social para las personas con discapacidad, inicial o sobrevenida, víctimas de violencia de género y víctimas del terrorismo que se establezcan como trabajadores por cuenta propia.

${ }^{70}$ Beneficios en la cotización a la Seguridad Social para las personas con discapacidad, inicial o sobrevenida, víctimas de violencia de género y víctimas del terrorismo que se establezcan como trabajadores por cuenta propia incluidos en el Sistema Especial para Trabajadores por Cuenta Propia Agrarios.

${ }^{71}$ Puede consultarse la Guía de recursos autonómicos en https://violenciagenero.igualdad.gob.es/violenciaEnCifras/Recursos_ Autonomicos/docs/Descripcion_Recursos_1.pdf
} 
reinserción laboral y de apoyo económico para las víctimas de violencia de género que se encuentran en situación de desempleo con el objetivo de promover su inserción laboral y proteger situaciones de falta de independencia económica.

De las previsiones de la LOVG pueden destacarse dos en este sentido.

Por un lado, el artículo 22 de la LOVG que estimó la necesidad de incluir un programa específico para las víctimas de violencia de género en situación de desempleo:

En el marco del Plan de Empleo del Reino de España, se incluirá un programa de acción específico para las víctimas de violencia de género inscritas como demandantes de empleo. Este programa incluirá medidas para favorecer el inicio de una nueva actividad por cuenta propia.

Por otro lado, el artículo 27 LOVG que estableció el derecho a percibir una ayuda económica a las víctimas de violencia de género que se encuentran en un determinado nivel de rentas y respecto de las que se encuentran en especiales dificultades para obtener un empleo ${ }^{72}$.

Finalmente, las víctimas de violencia de género han sido incluidas en programas autonómicos como colectivo específico requerido de apoyo económico y fomento de su empleabilidad, por cuenta propia o por cuenta ajena.

\subsubsection{Medidas que facilitan la inserción sociolaboral de las víctimas de violencia de género}

El plan específico al que se refiere el art. 22 LOVG se aprobó con el RD 1917/2008, de 21 de noviembre, por el que se aprueba el programa de inserción sociolaboral para mujeres víctimas de violencia de género que incluye un conjunto de medidas de políticas activas de empleo y su regulación ${ }^{73}$. Previamente se habían incluido algunas medidas de fomento de empleo -bonificaciones en las cuotas a la Seguridad Social en los supuestos de contratación de mujeres maltratadas- que no constituían un verdadero programa específico ${ }^{74}$.

Lo interesante de las propuestas es que van más allá de las bonificaciones de cuotas y/o subvenciones a las empresas, tradicionales medidas de fomento del empleo en el sistema español ${ }^{75}$.

\footnotetext{
${ }^{72}$ MELLA MÉNDEZ, L., "El programa estatal de inserción sociolaboral de las víctimas de violencia de género en España: una visión general”, en AAVV, Violencia de género y derecho del trabajo, Estudios Actuales sobre puntos críticos, citado, p. 275.

${ }^{73}$ GARCIA ROMERO, B., "La violencia de género desde la perspectiva del derecho del trabajo y de la seguridad social", en Aranzadi Social no 11/2012 (parte estudio).

${ }^{74}$ MELLA MÉNDEZ, L., "El programa estatal de inserción sociolaboral de las víctimas de violencia de género en España: una visión general”, en AAVV, Violencia de género y derecho del trabajo, Estudios Actuales sobre puntos críticos, citado, p. 276.

${ }^{75}$ Estas clásicas medidas de fomento también se prevén para la contratación de las víctimas en el art. 21.3 de la LOVG, y en la Ley 43/2006. El artículo 21.3 LOVG establece una bonificación para las empresas que tengan que sustituir a una trabajadora víctima de violencia de género para los supuestos de suspensión de contrato o de movilidad geográfica "durante los períodos de reserva de puesto de trabajo. La empresa tendrá derecho a una bonificación del 100 por 100 de las cuotas empresariales a la Seguridad Social por contingencias comunes durante todo el período de suspensión o durante 6 meses en los supuestos de movilidad geográfica o de traslado. Por su parte, la Ley 43/2006, de 29 de diciembre, para la mejora del crecimiento y del empleo, establece bonificaciones a las contrataciones, indefinidas o temporales, de trabajadores que acrediten la condición de víctimas de violencia de género: el apartado 2 del artículo 1 de la Ley 43/2006 "de acuerdo con la redacción dada al mismo por la Ley 3/2012 regula con carácter excepcional bonificaciones para los contratos temporales que se celebren con personas que tengan acreditada la condición de víctima de violencia de género, o de víctima de violencia doméstica. De forma más concreta el artículo 2.4 de la Ley 43/2006 señala que los empleadores que contraten indefinidamente a personas que tengan acreditada la condición de víctima de violencia de género o de víctima de violencia doméstica, sin que sea necesaria la condición de estar en desempleo, tendrán derecho, desde la fecha de celebración del contrato, a una bonificación mensual de la cuota empresarial a la Seguridad Social. También en el caso de que se celebren contratos temporales con estas personas se tendrá derecho a una bonificación mensual de la cuota empresarial a la Seguridad Social o, en su caso, por su equivalente diario, durante toda la vigencia del contrato.
} 
En el apartado de medidas que pretenden facilitar la inserción sociolaboral de las víctimas desempleadas encontramos las siguientes:

- En primer lugar, se prevé un Itinerario de inserción sociolaboral, individualizado y realizado por personal especializado en los servicios públicos de empleo. La orientación deberá ser individualizada; se realizará por personal técnico especializado ${ }^{76}$ que será el responsable de su seguimiento y evaluación, coordinando las distintas acciones en las que participe hasta la inserción sociolaboral por cuenta ajena o propia. Se trata de crear puntos de atención especializada en las oficinas de empleo, para la atención personalizada y confidencial de las víctimas de violencia de género, desempleadas e inscritas como demandante de empleo, en función de sus recursos y circunstancias ${ }^{77}$. La realización de este itinerario específico y personalizado en atención a las circunstancias de la víctima parece básica, pues el perfil profesional y formativo de cada una de ellas podrá ser diferente, como también lo serán sus circunstancias personales, incluyéndose en dicho itinerario las acciones de orientación para el empleo ${ }^{78}$.

- En segundo lugar, y dentro del itinerario de inserción, es posible incluir un Programa formativo específico para favorecer la inserción sociolaboral por cuenta ajena, en el que se trabaje en aspectos personales en su caso, llevando a cabo actuaciones dirigidas a incrementar la autoestima y motivación para el empleo, y en aspectos profesionales de las mujeres participantes en el programa. Este programa contará con dos fases: una primera fase de preformación -en el que se tratará de desarrollar las habilidades sociales, destinado por tanto a las mujeres que carecen de formación o tienen especiales dificultades de incorporación al mercado de trabajo- y una segunda de formación profesional para el empleo -que incluye la participación en acciones de formación-. Este programa incluye el percibo de becas por asistencia durante la fase de formación - diez euros por día lectivogarantizándose un mínimo de ingresos durante el período formativo.

- Además se establecen incentivos para favorecer el inicio de una nueva actividad por cuenta propia. Los incentivos para favorecer el inicio de una nueva actividad por cuenta propia se concederán de acuerdo con lo previsto en la Orden TAS/1622/2007, de 5 de junio, por la que se regula la concesión de subvenciones al Programa de Promoción del Empleo Autónomo, o norma que la sustituya. Dicha orden establece que, en el supuesto de mujeres víctimas de violencia de género, las subvenciones y ayudas para el establecimiento como trabajadoras autónomas o por cuenta propia, al ser considerado uno de los colectivos con especiales dificultades de inserción laboral, se incrementarán hasta un 10\% respecto a las establecidas para las demás trabajadoras.

- Incentivos para las empresas que contraten a víctimas de violencia de género. La contratación de mujeres víctimas de la violencia de género es objeto de bonificación en las cuotas a la seguridad social, tanto si es indefinida como temporal, según lo establecido en el artículo 2.4 de la Ley 43/2006 de 29 de diciembre, para la mejora del crecimiento y del empleo.

Otra forma de inserción laboral de las víctimas de violencia de género es a través de las denominadas empresas de inserción. Esta opción, que proporciona un trabajo remunerado y formación,

\footnotetext{
${ }^{76}$ Debe valorarse positivamente que se exija que el personal especializado que se hará cargo de la elaboración del itinerario también será el responsable de su seguimiento y evaluación.

${ }_{77}$ GARCIA ROMERO, B., "La violencia de género desde la perspectiva del derecho del trabajo y de la seguridad social", en Aranzadi Social no 11/2012 (parte estudio).

${ }^{78}$ MELLA MÉNDEZ, L., "El programa estatal de inserción sociolaboral de las víctimas de violencia de género en España: una visión general”, citado, p. 281.
} 
está prevista para las mujeres víctimas de violencia de género que se encuentren en situaciones de exclusión social. Es la Ley 44/2007, de 13 de diciembre, la que contiene la regulación del régimen de las empresas de inserción. La Ley 44/2007 tiene por objeto regular el régimen jurídico de las empresas de inserción y establecer un marco que promueva la inserción laboral de personas en situación de exclusión social a través de este tipo de empresas. Tendrá la consideración de empresa de inserción aquella sociedad mercantil o sociedad cooperativa legalmente constituida, calificada por los organismos autonómicos competentes en la materia, y que realice cualquier actividad económica de producción de bienes y servicios, cuyo objeto social tenga como fin la integración y formación sociolaboral de personas en situación de exclusión social como tránsito al empleo ordinario. Las empresas de inserción deberán proporcionar a los trabajadores procedentes de situaciones de exclusión social previstas en las normas, como parte de sus itinerarios de inserción, procesos personalizados y asistidos de trabajo remunerado, formación en el puesto de trabajo, habituación laboral y social. Asimismo, estas empresas deberán tener servicios de intervención o acompañamiento para la inserción sociolaboral que faciliten su posterior incorporación al mercado de trabajo ordinario.

\subsubsection{Medidas que facilitan el trabajo por cuenta ajena de las víctimas de violencia de género}

El segundo conjunto de medidas trata de facilitar la realización de un trabajo por cuenta ajena, bien sea a través de incentivos a la movilidad de las trabajadoras que cambian su residencia o compensación de diferencias salariales, en relación a trabajos por cuenta ajena que la trabajadora abandona consecuencia de su condición de víctima. Estas son las condiciones establecidas:

A) Incentivos para facilitar la movilidad geográfica. Las mujeres que, como consecuencia de su contratación, tengan que trasladar su residencia habitual, podrán recibir subvenciones por movilidad geográfica para financiar los gastos derivados de dicho traslado. A estos efectos, se considera que existe movilidad geográfica cuando, como consecuencia de la contratación, se produzca un traslado efectivo de la residencia habitual de la trabajadora a una localidad de destino que se encuentre a más de 50 Kilómetros de la localidad de origen, excepto cuando se trate de desplazamientos con destino u origen en Ceuta o Melilla o desplazamientos interinsulares, efectuados entre cualquiera de las islas de cada uno de los archipiélagos, en los que la distancia podrá ser inferior -artículo 10 del Real Decreto 1917/2008-.

Por su parte, la norma trata de atender los gastos generados por diferentes conceptos y así se subvencionan los siguientes: gastos de desplazamiento ${ }^{79}$; gastos de transporte de mobiliario y enseres ${ }^{80}$; gastos de alojamiento ${ }^{81}$; gastos de guardería y de atención a personas dependientes ${ }^{82}$.

${ }^{79}$ Estas subvenciones se destinarán a cubrir los gastos de desplazamiento de la beneficiaria, así como los de los familiares a su cargo que convivan con ella, desde la localidad de origen a la del nuevo destino. Cuando el desplazamiento se realice en línea regular de transporte público la cuantía máxima de la ayuda será el importe del billete o pasaje dentro de la tarifa correspondiente a la clase segunda, turista o equivalente. Si se utiliza para el desplazamiento el vehículo particular la cuantía máxima de la ayuda será la establecida al efecto en las administraciones públicas como indemnización por uso de vehículo particular, a la que se añadirá el importe de los peajes que se justifiquen

${ }^{80}$ Por el traslado de mobiliario y enseres, desde la localidad de origen a la del nuevo destino, en la cuantía del coste de dicho traslado, hasta un máximo de 4 veces el Indicador Público de Renta de Efectos Múltiples mensual vigente

${ }^{81}$ Estas subvenciones se destinarán a cubrir gastos generados por el alojamiento, incluyendo el alquiler o adquisición de vivienda u otros gastos de hospedaje, de la beneficiaria y de los familiares a su cargo que convivan con ella, en la localidad de nuevo destino, durante los doce primeros meses de vigencia del contrato. La cuantía máxima de la ayuda será de 10 veces el IPREM mensual vigente

${ }^{82}$ Estas subvenciones se destinarán a cubrir gastos por asistencia a guarderías o centros de enseńanza durante el primer ciclo de educación infantil de los hijos de la beneficiaria que dependan económicamente de la misma o por atención de las personas depen- 
B) Incentivos para compensar diferencias salariales. Con esta medida se trata de atender a la víctima de violencia de género que abandona un puesto de trabajo como consecuencia de su condición de víctima, y accede a otro compatible con su situación personal. Así se señala que tendrán derecho a estos incentivos las mujeres cuyo contrato laboral se haya extinguido por decisión de la trabajadora que se vea obligada a abandonar definitivamente su puesto de trabajo como consecuencia de ser víctima de violencia de género, según lo establecido en el artículo 49.1.m de la Ley del Estatuto de los Trabajadores, y el contrato subsiguiente que formalicen, ya sea indefinido o temporal, con una duración efectiva igual o superior a seis meses, implique una disminución salarial ${ }^{83}$. La disminución se mide comparando las bases de cotización -anterior y posterior-, teniendo así derecho a recibir con carácter mensual una cuantía equivalente a la diferencia existente entre aquellas, por un importe máximo de 500 euros mensuales durante doce meses, de manera que durante el primer año del nuevo contrato no sufra perjuicio económico ${ }^{84}$.

C) Convenios con empresas para facilitar la contratación de mujeres víctimas de violencia de género y su movilidad geográfica. También se diseñan acciones destinadas a facilitar la contratación de las víctimas de violencia de género (artículo 12 del real Decreto 1917/2008). En este sentido, se prevé que la Delegación del Gobierno para la Violencia de Género promoverá la suscripción de convenios de colaboración con empresas para fomentar la sensibilización sobre la violencia de género y la inserción laboral de las víctimas, con el fin de facilitar la contratación a las mujeres víctimas de violencia de género y la movilidad geográfica, para aquellas que tengan necesidad de trasladar su residencia con la garantía de un empleo. Además, se prevé que la Delegación del Gobierno para la Violencia de Género difundirá estos convenios entre los Servicios Públicos de Empleo, y otros órganos y entidades que atienden a este colectivo, al objeto de que, se realicen las gestiones necesarias para poner en contacto a la mujer con las empresas a fin de promover su colocación. En cada Convenio se establecerá una Comisión de Seguimiento. Las empresas que celebren contratos en el marco de estos Convenios informarán de los mismos a la Comisión de Seguimiento del Convenio, a fin de que ésta realice el seguimiento y análisis del funcionamiento de esta medida y de su efectividad.

\subsubsection{Medidas de apoyo económico para las víctimas de violencia de género}

El Pacto de Estado contra la violencia de género de 2017 incluye una serie de 11 ejes de actuación entre las que es destacable a los efectos que nos ocupan el eje 3, que señala

\footnotetext{
dientes a su cargo, generados durante los doce primeros meses de vigencia del contrato. La cuantía máxima de la ayuda será de 4 veces el IPREM mensual vigente

${ }^{83}$ Cuando la base de cotización resultante del nuevo contrato de la trabajadora sea inferior a la del anterior contrato extinguido, la trabajadora tendrá derecho a percibir por meses una cuantía equivalente a la diferencia entre ambas bases de cotización, por un importe máximo de 500 euros/mes y durante un tiempo máximo de doce meses. A efectos del cálculo de la diferencia se considerará el promedio de las bases de cotización para accidentes de trabajo y enfermedades profesionales, excluida la retribución por horas extraordinarias, durante los seis meses o periodo de tiempo inferior anteriores a la fecha de extinción del contrato anterior y el promedio de las bases de cotización siguientes a la fecha de vigencia del nuevo contrato, por periodos de seis meses. En el supuesto de que el último contrato de la trabajadora, el nuevo contrato o ambos sean a tiempo parcial, el cálculo se efectuará de forma proporcional a la jornada habitual o a tiempo completo.

${ }^{84}$ MELLA MÉNDEZ, L., "El programa estatal de inserción sociolaboral de las víctimas de violencia de género en España: una visión general”, citado, p. 292.
} 
"El perfeccionamiento de la asistencia, ayuda y protección que se ofrece a las mujeres víctimas de la violencia de género y a sus hijos e hijas. Para ello se revisarán los planes de atención a las víctimas garantizando un tratamiento personalizado, se potenciarán y adecuarán los recursos existentes y se facilitará el acceso a los mismos de todas las mujeres (...). Se potenciarán también los planes de inserción laboral de mujeres víctimas, implicando activamente a los agentes sociales, y se simplificarán y mejorarán los sistemas de ayudas previstos actualmente.".

Al respecto de las medidas de apoyo económico son dos las vías que permiten encontrar soluciones para las víctimas de violencia de género: una se relaciona con el sistema de seguridad social, a través de la protección de desempleo, protección que incluye el acceso a la prestación de nivel contributivo cuando las víctimas resuelvan o suspendan voluntariamente su contrato de trabajo como consecuencia de la violencia de género (artículo 21.2 de la LOVG y, en su desarrollo el art. 267.1.a. $5^{\circ}$ y 1.b.2 $2^{\circ}$ de la LGSS), pero también, y, en desarrollo de las previsiones del actual art. 265.2 de la LGSS, la renta activa de inserción, que forma parte de la acción protectora por desempleo del régimen público de Seguridad Social, si bien con carácter específico y diferenciado del nivel contributivo y asistencial (RD 1369/2006, de 24 de noviembre), y que entre sus beneficiarios incluye a quienes detenten la condición de víctima de violencia de género o doméstica, salvo cuando convivan con el agresor, inscritas como demandante de empleo ${ }^{85}$.

Junto a las anteriores previsiones, se disponen ayudas específicas en la propia LOVG -art. 27-, en el Real Decreto-ley 20/2020, de 29 de mayo, por el que se establece el ingreso mínimo vital, y en las correspondientes normas de desarrollo de carácter autonómico, al situarnos en el ámbito de la asistencia social.

En efecto, como se había anunciado es preciso hacer referencia a la ayuda económica prevista en el art. 27 LOVG que establece el derecho a percibir ayuda económica a las mujeres víctimas de violencia de género, que se encuentran en un determinado nivel de rentas y respecto de las que se presuma se encuentran en especiales dificultades para obtener un empleo. Se exige así el cumplimiento de dos requisitos: a) Carecer de rentas que, en cómputo mensual, superen el 75 por ciento del salario mínimo interprofesional vigente, excluida la parte proporcional de dos pagas extraordinarias; b) Tener especiales dificultades para obtener un empleo, que se acreditará a través del Informe del Servicio Público de Empleo ${ }^{86}$.

Se trata de una manifestación de la garantía de los derechos económicos de las víctimas de violencia de género que establece el art. 2.e de la LOVG. El desarrollo de este precepto legal se produce en el Real Decreto 1452/2005, de 2 de diciembre, y aunque las ayudas se financian con cargo a los Presupuestos Generales del Estado, son concedidas y abonadas en un pago único por las Administraciones competentes en materia de servicios sociales, de conformidad con sus respectivas normas de procedimiento ${ }^{87}$. A estos efectos cada CCAA ha desarrollado reglamentariamente el art. 27 LOVG $^{88}$,

\footnotetext{
${ }^{85}$ Programa gestionado por el Servicio Público de Empleo en colaboración con los servicios públicos de empleo de las comunidades autónomas que tiene por finalidad servir de apoyo a la inserción laboral de colectivos con dificultades de incorporación al mercado de trabajo y en situación de necesidad económica. SELMA PENALVA, A, "La incidencia de la violencia de género sobre las normas laborales", en Actualidad Laboral, n 18, 2011. Esta forma de protección se sitúa dentro del sistema de protección por desempleo y se vincula al agotamiento de las opciones protectoras de nivel contributivo y asistencial, con la finalidad de protección de desempleados con dificultades especiales. BASTERRA HERNÁNDEZ, M., "De la protección frente al desempleo a la renta básica universal: un análisis comparativo entre España y Portugal”, Revista de Información Laboral num.12/2018, p. 8 de 25

${ }^{86}$ Según los últimos datos publicados por la Delegación del Gobierno para la Violencia de Género, en el período 2006-2017 se concedieron 5.393 ayudas económicas; destacan las 1.157 concedidas en el País Vasco (21.5\% del total) y las 816 de la Comunitat Valenciana (15,1\%), datos que pueden consultarse en https:/violenciagenero.igualdad.gob.es/violenciaEnCifras/observatorio/informesAnuales/informes/cap_XI/Cap10_Art.27_2017.pdf

${ }^{87}$ SERRANO ARGÜESO, M., “¿Por qué la elección entre inserción laboral o ayudas económicas específicas?, citado, p. 427.

${ }^{88}$ A modo de ejemplo véase la Orden de 3 de mayo de 2007, de la Conselleria de Bienestar Social, por la que se regula la ayuda
} 
pero cabe destacar que se trata de ayudas incompatibles con la renta activa de inserción, así como con la prestación y el subsidio por desempleo; incompatibilidad que se ha relacionado con la empleabilidad de las víctimas, pues la ayuda económica del art. 27 LOVG se otorga por considerar a las víctimas transitoriamente inempleables ${ }^{89}$. Así, una de las críticas más fundamentadas que se ha efectuado a esta ayuda económica es la necesaria vinculación a la situación de desempleo de las mujeres, cuando debiera hacerse al incremento de gastos que conlleva la ruptura de la relación de violencia ${ }^{90}$.

También se refiere a la misma el Pacto de Estado en materia de violencia de género de 2017, que señala la necesidad de "Estudiar el actual sistema de ayudas de la Renta Activa de Inserción del artículo 27 de la LO 1/2004, para mejorar la situación de las mujeres víctimas sin empleo, y evaluar su sustitución por un subsidio de desempleo de seis meses de duración, que se ampliará por periodos semestrales prorrogables, siempre que las personas beneficiarlas continuaran cumpliendo con los requisitos para continuar percibiéndolo. Estas ayudas se financiarán con cargo a los Presupuestos Generales del Estado" ${ }^{91}$.

Por su parte, debe también traerse a colación el Real Decreto-ley 20/2020, de 29 de mayo, que aprueba el ingreso mínimo vital, prestación dirigida a prevenir el riesgo de pobreza y exclusión social de las personas que vivan solas o integradas en una unidad de convivencia, cuando se encuentren en una situación de vulnerabilidad por carecer de recursos económicos suficientes para la cobertura de sus necesidades básicas, que puede tener repercusión para las víctimas de violencia de género, ya que para este colectivo introduce requisitos específicos que suavizan la edad mínima de acceso (art. 5), la consideración de unidad de convivencia (art. 6), los propios requisitos de acceso (art. 7) o los criterios para la determinación de la cuantía (art. 10).

\section{Conclusiones y propuestas para perfeccionar la asistencia, ayuda y protección laboral de las víctimas de violencia de género}

Del análisis de las medidas descritas cabe extraer algunas conclusiones respecto de las que pueden hacerse propuestas de mejora del sistema de asistencia, ayuda y protección a las víctimas de violencia de género:

1. En primer lugar, la mayor evidencia es la necesidad de implicar de forma más activa a las empresas, con el objetivo de facilitar el ejercicio de las medidas laborales en el ámbito de la empresa, y para ello parece necesaria la aprobación de protocolos de actuación para la atención de las víctimas de violencia de género. Se trata de garantizar una mayor eficacia en la protección de las víctimas de violencia de género, de acoso sexual y de acoso por razón de sexo, pues como se sabe no existen derechos si no existen procedimientos adecuados que los garanticen y sanciones disuasorias de su violación ${ }^{92}$. Parece necesario fomentar la implicación de las empresas y orientar su respuesta ante la violencia de género, su prevención, sanción y la protección de las víctimas, como aspectos clave de la responsabilidad social corporativa. En este sentido deben impulsarse los procedimientos colectivos de negociación en la empresa, sea a través de la negociación colectiva, de la negociación

económica a favor de las víctimas de violencia de género, establecida en el artículo 27 de la Ley Orgánica 1/2004 de 28 de diciembre, de Medidas de Protección Integral contra la Violencia de Género

${ }^{89}$ SERRANO ARGÜESO, M., “¿Por qué la elección entre inserción laboral o ayudas económicas específicas?, citado, p. 428-429.

${ }^{90}$ SERRANO ARGÜESO, M. “`Por qué la elección entre inserción laboral o ayudas económicas específicas?, citado, p. 437.

${ }^{91}$ p. 254 de 277.

${ }^{92}$ La expresión es de PÉREZ DEL RIO, MaT., La violencia de género en el ámbito laboral: el acoso sexual y el acoso sexista, citada, p. 81. 
de Planes de Igualdad o de la introducción de protocolos específicos para la gestión de los derechos de las víctimas de violencia de género ${ }^{93}$. El objetivo es anticipar la resolución de conflictos y agilizar el acceso a los derechos destinados a garantizar su protección o su derecho a la asistencia social integral. Así, en caso de desacuerdo o discrepancias entre el empresario y la trabajadora la remisión a la vía judicial no puede convertirse en la única vía de resolución, debiendo propugnarse el establecimiento de mecanismos de resolución de discrepancias con vistas a conseguir un acuerdo, lo que podría integrar el contenido del convenio colectivo o del plan de igualdad de las empresas. El Real Decreto 901/2020, de 13 de octubre, por el que se regulan los planes de igualdad y su registro, y se modifica el Real Decreto 713/2010, de 28 de mayo, sobre registro y depósito de convenios y acuerdos colectivos de trabajo, es un buen punto de partida para el desarrollo que se propone.

Debe recordarse que el Real Decreto-ley 6/2019, de 1 de marzo, de medidas urgentes para garantía de la igualdad de trato y de oportunidades entre mujeres y hombres en el empleo y la ocupación, incorporó cambios muy significativos en la LOI en materia de planes de igualdad, además de la necesidad de realizar un diagnóstico. Tanto los planes de igualdad como los diagnósticos previos deben ser objeto de negociación con la representación legal de las personas trabajadoras (comité de empresa, las delegadas y los delegados de personal, en su caso, o las secciones sindicales si las hubiere que, en su conjunto, sumen la mayoría de los miembros del comité). Además, junto al contenido mínimo de los Planes de Igualdad, se incorpora una previsión de contenido adicional relativo a materias no enumeradas en el artículo 46.2 de la LOI, entre las que se señala la violencia de género (art. 8.3 RD 901/2020). Finalmente, en el sentido planteado, se prevé como posible contenido del Plan de Igualdad la incorporación de un procedimiento para solventar las posibles discrepancias que pudieran surgir en su aplicación, seguimiento, evaluación o revisión (art. 8.2.k RD 901/2020).

Igualmente, deben promoverse en las empresas medidas y procedimientos que garanticen unas condiciones de trabajo exentas de violencia y acoso dentro del ámbito de organización y dirección de la empresa, ya se trate de violencia ejercida por directivos o jefes, otros trabajadores o personas relacionadas con la empresa, así como arbitrar mecanismos de prevención y de denuncia o reclamación en caso de violencia en el lugar de trabajo. Así, se ha señalado la necesidad de que las empresas atiendan y protejan la situación de violencia de género, tanto las que se produzcan en los lugares de trabajo como las que tienen lugar fuera de tiempo y lugar de trabajo, a través del impulso de protocolos oportunos para su detección y actuación ${ }^{94}$.

2. En segundo lugar, parece necesario garantizar que las víctimas no sufran pérdida económica por el ejercicio de los derechos laborales reconocidos a las víctimas trabajadoras, circunstancia que no se consigue en todos los casos --por ejemplo si se opta por hacer uso de los permisos reconocidos o del derecho a la reducción de jornada-. Para ello debe revisarse el sistema de ayudas económicas, atendiendo a la situación de necesidad derivada de la violencia, que puede estar vinculada o no a la situación de empleo de la víctima. Hemos

\footnotetext{
${ }^{93}$ Puede consultarse la Guía práctica para el abordaje de la violencia de género en la empresa en https://lagroc.com/app/ uploads/2018/05/CARVEguideCAST.pdf que incluye una compilación de las mejores prácticas para abordar la violencia de género en el ámbito laboral, Guía coordinada por Dimitris Micharikopoulos y Elena Tavlaki.

${ }^{94}$ SERRANO ARGÜESO, M., “¿Por qué la elección entre inserción laboral o ayudas económicas específicas? Lo que el Pacto de Violencia de Género no ha sido capaz de ver”, citado, p. 421. Pueden consultarse modelos de protocolos en el ámbito de las empresas en https://www.auditoressociolaborales.com/protocolo2.php
} 
observado que las ayudas económicas se destinan principalmente a atender la situación de desempleo de las víctimas, pero no es ésta la única situación de necesidad atendible.

3. Igualmente se juzga oportuno plantear, a nivel legislativo, la extensión de la protección a otras víctimas de violencia por razón de género, no contempladas en la LOVG, esto es, aquellas que no son agredidas por su pareja o expareja, sino por otros familiares, compańeros de trabajo o superiores jerárquicos, y que en la actualidad no tienen reconocidos los mismos derechos o medidas laborales de protección las víctimas de acoso en el trabajo que las víctimas de violencia de género. Igualmente parece imprescindible la ampliación de los derechos laborales a las víctimas de violencia vicaria o violencia "por interpósita persona" 95. La extensión se ampararía en el Convenio del Consejo de Europa sobre prevención y lucha contra la violencia contra la mujer y la violencia doméstica, hecho en Estambul el 11 de mayo de 2011, como se ha argumentado supra.

4. Finalmente, es preciso igualmente impulsar la contratación de mujeres en empresas privadas o en sector público, ya sea a través de la potenciación de los planes de inserción laboral de mujeres víctimas, ya a través de la inclusión de cláusulas sociales en la contratación pública al amparo de las previsiones de la Ley de contratos del sector público, Ley 9/2017, de 8 de noviembre.

${ }^{95}$ Tal y como se plantea en el Informe de la subcomisión creada en el seno de la comisión de igualdad para un pacto de estado en materia de violencia de género https:/violenciagenero.igualdad.gob.es/pactoEstado/docs/PactodeEstado_Congreso.pdf 